\title{
Eco-Forecasting for Domestic Electricity Use
}

\author{
Jesper Kjeldskov, Mikael B. Skov, Jeni Paay, Dennis Lund, Tue Madsen, Michael Nielsen \\ Department of Computer Science / Research Centre for Socio+Interactive Design \\ Aalborg University, Aalborg East, Denmark \\ \{jesper, dubois, jeni\}@cs.aau.dk
}

\begin{abstract}
Over the past decade we have seen an increased awareness about domestic energy consumption and a growing focus on eco-feedback displays. In this paper we explore the concept of providing forecasts in such displays as a supplement to information about past usage. Our prototype, eForecast, extends the display of past electricity usage with forecasts about expected usage, electricity price, availability of wind power, and expected demand drops and peaks. Building on previous eco-feedback display research, our approach specifically enables people to use electricity at more opportune times - when it is cheap, green, or when there is an abundance of capacity. We evaluated eForecast in real world use in three domestic households for 22 weeks, where we explored potentials and limitations of forecasting for shifting electricity consumption. In this way, families were able to act in a more sustainable way - without necessarily reducing the amount of electricity consumed.
\end{abstract}

\section{Author Keywords}

Sustainability; forecasting; energy consumption; domestic

\section{ACM Classification Keywords}

H.5.m. Information interfaces and presentation (e.g., HCI): Miscellaneous.

\section{INTRODUCTION}

Sustainability has in recent years become an area of interest in $\mathrm{CHI}$ research exploring, amongst others, the design and use of "eco-feedback displays" for informing people about their consumption of various precious resources, such as water and electricity. The motivation behind eco-feedback displays is that by making the consumption of resources more evident and accessible, people are able to reflect on their usage, and possibly reduce it. This potentially leads to monetary savings for the individual consumer and to better environmental sustainability for society. While such ecofeedback displays offer a lot of functional advantages over traditional out-of-sight metering of utilities, such as being able to see when and where resources were used, the

\section{Permission to make digital or hard copies of all or part of this work for personal or classroom use is granted without fee provided that copies are not made or distributed for profit or commercial advantage and that copies bear this notice and the full citation on the first page. Copyrights for components of this work owned by others than ACM must be honored. Abstracting with credit is permitted. To copy otherwise, or republish, to post on servers or to redistribute to lists, requires prior specific permission and/or a fee. Request permissions from Permissions@acm.org.}

CHI 2015, April 18 - 23 2015, Seoul, Republic of Korea Copyright 2015 ACM 978-1-4503-3145-6/15/04 ...\$15.00 http://dx.doi.org/10.1145/2702123.2702318 information provided is generally retrospective. This means that little input is given on how to act in order to become, or remain, environmentally sustainable. While several studies have reported positive user reactions to such eco-feedback displays, research has not yet shown clear evidence that they reliably cause people to actually take action or change behaviour [10]. Another limitation of the traditional ecofeedback approach is that the underlying goal of reduction only addresses one side of the challenge of sustainability. While it is, of course, good to lower our use of resources, for some types of them, such as electricity from renewable energy sources, the challenge facing us is also a matter of being able to use it at the right time.

One problem with "green" electricity like wind turbines or solar panels is that the level of supply is not controllable or constant but relies on weather conditions. Therefore there is sometimes a low level of supply, while at other times more electricity is produced than being used. Since no technology exists for efficiently storing large amounts of electricity, this surplus of energy is simply lost. This leaves a currently underexplored potential for improved sustainability. If we can enable people to shift [8] some of their electricity consumption to more favourable times, then we can also reduce the use of electricity generated from conventional fuels - even without necessarily reducing our absolute consumption. In order to do this, however, people need to know when those favourable times are, when their pattern of usage is not ideal, and when it would be good to act differently. This is very different from what is currently provided by retrospective eco-feedback systems.

Here we present a case study in this new area, looking at eco-feedback displays for domestic electricity use from the angle of forecasting by exploring the ability to provide relevant information about the near future. Electricity is a particularly interesting case for this because several factors influence if usage is favourable or not. While the use of renewable electricity sources (e.g. wind) is obviously preferable for the environment, it is also preferable to avoid large peaks in demand, as this will challenge the capacity, and hence the sustainability, of the power grid. From the consumer's perspective, time-based electricity prices also make it preferable to use power when it is cheap. For this case we have developed an eco-forecasting display with information about availability of green energy sources, capacity in the grid, the price, and evaluated in domestic settings. We describe the design of the system, details of the deployment, and present and discuss our findings. 


\section{BACKGROUND}

Previous work on sustainability within CHI falls primarily within what Mankoff et al. [5] refer to as sustainability through design, aiming to deploy technology facilitating sustainable behaviour. Much of this work focuses on "ecofeedback" to help people reduce resource consumption or environmental impact by showing information about usage and behaviours in the past [2]. Froelich et al. [3] did an evaluation of eco-feedback displays for water usage at fixture level in North America examining design elements such as data and time granularity. The study showed great interest in this level of data detail, but also that additional information would be needed to facilitate changes, such as comparisons over time, and with others, for contextualizing performance. Also focussing on water use, Pathmanathan et al. [6] investigated eco-feedback on mobiles for promoting water conservation in Australia. This study found that while information about past water usage might reveal patterns, and be useful as context for future usage, it is not in itself sufficient for enabling people to behave environmentally sustainably in the present or near future. In a similar study, Kjeldskov et al. [4] investigated eco-feedback on domestic electricity use in Denmark, finding that in order to help people change behaviour, or continue good behaviour, other information than retrospective is needed, in particular, cues on how to act in the present and near future. Also focussing on domestic energy consumption, based on interviews and surveys, Pierce et al. [8] present a vocabulary of terms capturing actions and strategies of energy conservation including shifting it. In [7] this is extended with a review of energy related work in which the idea of using energy differently by, for example, shifting consumption informed by demand response system is further discussed. Also influencing the eco-feedback research agenda Strengers [10] shows how domestic energy use is deeply embedded in non-negotiable everyday practices and not reflected well by the view on families as potential "micro-resource managers". Together, these works have contributed to defining as well as broadening the scope of interactive system design for eco-feedback and sustainability.

Responding to these insights on eco-feedback, Yang et al. [11] studied people's interactions with conventional ecointelligent thermostats in domestic households, and propose the use of eco-feedforward to communicate actionable suggestions and their expected impact. Also aiming at being prospective rather than retrospective, Costanza et al. [1] explore the use of a washing machine agent, using data on future electricity price, combined with chargeable batteries, to minimize the cost of a wash. Similarly, Schrammel et al. [9] discuss the use of basic power generation forecasts for helping users align energy consumption with availability.

\section{Forecasting}

Building on this related work, our approach to eco-feedback displays is to use forecasting as a form of prospective ecofeedforward that enables people to act more favorably in their use of resources. By forecasting we refer to the process of making assertions about occurrences that have not yet happened, or whose actual outcomes have not yet been observed. Forecasting is used for many purposes, such as climate, energy, economics, production planning etc. and comes in several variants, for example naive, time-seriesbased, judgmental, and causal methods. In the context of facilitating sustainable domestic electricity use, several forecasts may be of value. Weather forecasting can inform us about imminent availability of wind and sun power, demand forecasting can tell us about forthcoming capacity, and electricity market models can give us a rather precise picture of the hourly electricity price within the next 24 hours. Data on past electricity use can inform forecasts about expected patterns of consumption in the future.

\section{eFORECAST}

Our prototype, eForecast, is similar to the idea in [9] but extends this with several sources of forecasts and a system deployment. We designed and created eForecast to present recent usage, expected usage, electricity price, availability of wind power, and expected peaks in demand. eForecast is designed to run on an always-on tablet that can be placed in a suitable place in the home e.g. on a shelf or mounted on the wall. eForecast is not meant to include a lot of detail about past electricity usage. Instead the aim here is to empower people to respond to some of the external factors that influence the sustainability of electricity use.

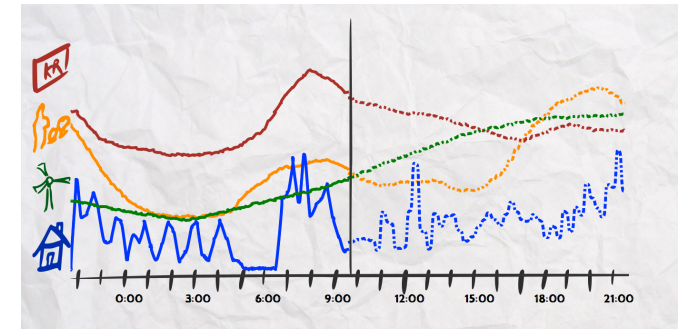

Figure 1. Screenshot: historical data (solid lines) and forecast (dotted lines) for the household's consumption (blue), wind power (green), grid capacity (yellow) and price (red)

eForecast consists of six different screens, which the user can swipe between. Four of these screens display different visualizations of the household's recent electricity usage combined with forecasts from external sources. The fifth screen shows all forecasts combined (Figure 1). The vertical line in the middle indicates current time, with the last 12 hours represented on the left (solid line), and the forecast for the next 12 hours on the right (dotted line). In this example it can be seen that the household has an expected peak of electricity use just after 12:00 and an increase in use after 19:00 (blue), and that there will be an increase in available wind power during the afternoon, leveling out after 18:00 (green). Price will go down until 17:00 (red), and demand is expected to go up after 15:00 (yellow). It can also be seen that there is a "sweet spot" between 16-17:00 where price and demand is low while the availability of wind power is high. Based on this, one might attempt to delay the 12-13:00 peak in use by a few hours. 


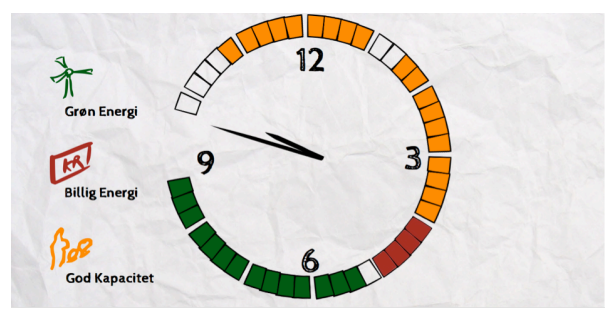

Figure 2. Clock with eco-forecast.

In order to provide people with a simple overview, a dedicated screen displays a clock with a simplified indication of upcoming time-periods where it would be favorable to use electricity - either because it is green, cheap, or in good capacity. This is illustrated in Figure 2.

\section{Implementation}

eForecast has two components: a client application that displays the data to the user, and a server that collects and manages data from different sources. Electricity use data is collected from a home automation system, ZenseHome, which contains real-time measurements from the individual power outlets in the house. This is used to record, display and predict usage in 15-minute intervals. Electricity price data is collected using web scraping of Northern Europe's leading power market, Nord Pool Spot, where electricity pricing is negotiated at least 12 hours in advance. Data on the expected availability of wind power is based on weather forecasts from the Open Weather Map weather service. The expected demand on the power grid is calculated on the basis of data about similar households' combined patterns of consumption, taking into account the day of the week, and the month of the year. The household's expected energy demand is calculated in the same manner but based on their own history of use.

\section{EVALUATION}

We tested eForecast in a longitudinal trial deployment with three Danish households over the spring and summer of 2014. Our main aim of the trial deployment was to test the approach of providing eco-feedback forecast information in real world domestic settings, and to gain qualitative feedback from users. For this purpose it was important for us that the households had the eForecast system in their home for enough time to avoid the initial news effect, and let it possibly be integrated into their daily lives.

\section{Participants}

We recruited three families in the region to participate in a longitudinal study of domestic electricity use. The families all had the ZenseHome system installed in their house required for collecting usage data, but had no eco-feedback system. Household 1 was a married couple in their thirties with 3 children aged 4 and 1 (twins). Household 2 was a married couple in their early forties with no children. Household 3 was a married couple in their forties with two children aged 10 and 16. The families came from different towns, and did not know each other. They were all middleclass households, with both parents in permanent jobs.

\section{Procedure}

The trial deployment lasted 22 weeks, and involved 121 hour semi-structured interviews ( 4 with each family). To sustain interest in the system we introduced the screens in steps. At the beginning of the study the only screens enabled were individual forecasts on price, wind power and capacity. After two weeks we enabled the combined forecast (Figure 1) and after four weeks we enabled the clock-based forecast (Figure 2). The interviews were conducted by three researchers and focused on the families' perceptions and use of the system, and on their electricity use behavior and understanding. We asked them questions about how they interpreted the information presented; how it fitted their picture of electricity use in the household; how electricity usage was tied to their daily routines; what usage they would and wouldn't be able to shift; if, how and when the system had enabled them to shift electricity use; and what factors had played a role in this. The interviews were recorded, transcribed, and coded for thematic analysis.

\section{Findings}

All participating families enjoyed using the system, and kept using it throughout the duration of the deployment. We logged a total of 631 user interactions, distributed over the 22 -week period. For creating the eco-forecasts, the system gathered approximately 2.4 million electricity consumption entries, 4058 price data entries, and 1475 wind data entries. The interviews showed that forecasting in the eco-feedback display facilitated not only insight on consumption patterns, but also awareness and understanding of the context of electricity use, and some of the factors that may contribute to improved sustainability. People were generally intrigued by the idea that they could contribute to sustainability not only by reducing electricity use but also by using it at particular times. They were also attracted to the idea that those times could be seen from the relatively simple forecasts provided through the system. Hence, although we could not measure quantitatively significant changes in consumption patterns, the study showed that forecasting did indeed enable people to identify opportunities for shifting electricity use to more favorable times.

All families reported that they were able to understand the forecasts, and that the forecasting element gave them an added value over traditional backward looking ecofeedback displays. For this, it was expressed that the screen with combined forecasts was most useful because this view allowed people to consider different forecasted tendencies up against each other, for example, when electricity was going to be both green and cheap. In relation to this, the forecast information on the clock screen was sometimes too simplistic on its own, as it did not reveal this level of detail, but only gave an overall indication of upcoming favorable times for electricity usage. This meant that people had to check the detailed forecast view in order to fully understand why the clock had marked out a particular time period as good for using electricity. However, it was also reported that the system was often left displaying the clock screen, 
rather than the graphs, because this screen was useful more generally, and provided a central and easily accessible point of entry to the eco-forecast. In discussing the different forecasts in relation to each other, all families expressed that the greatest motivational factor for shifting electricity use was reduced costs. While they all understood the positive environmental effects of using green electricity, they expressed that since they were paying the same for power independent of origin and grid capacity, they were entitled to use it when it suited them best, and not when it would be best for the utility provider. To motivate people shifting electricity use to more sustainably favorable times, there needed to be an economical reward.

Use of the system also prompted discussions about what appliances and devices the families would be able to use flexibly in light of eco-forecasts. All families expressed that during the study they had found some appliances so tightly coupled to the family's daily routines, for example for cooking and for entertainment, that they were very difficult to shift in time. It was reported as particularly difficult to shift electricity use in the mornings of weekdays (e.g. the use of coffee machines and toasters) because people were typically on a tight schedule to get to work or school then. The use of other appliances, like dishwashers, washing machines, and battery chargers for mobile devices, was however considered very flexible, as they would typically run in the background, and not be part of an activity. Being out of focus, however, these also presented new challenges: although enabling the families to see opportune times for using electricity, it was reported that when planning to move the running of an "electricity-hungry" appliance to a later time (like a dishwasher or washing machine), they sometimes forgot to actually set it off when that time came.

\section{DISCUSSION AND CONCLUSIONS}

The contribution of this work is a pilot study of the concept of forecasting in eco-feedback displays, and insights about potentials and challenges of this in relation to facilitating sustainability in domestic electricity use. We have presented a prototype system, eForecast, designed and deployed to investigate potentials for shifting parts of a household's electricity usage to more favorable times. Our study confirms some of the thoughts in [7, 8, 9] that ecoforecasting has potentials for enabling people to shift some of their electricity use, and that people understand and like this idea. They would, however, expect a financial reward for their effort. At the same time, our results also confirm the findings in [8] and [10] that shifting domestic electricity use is challenging. Electricity use in the home is closely related to family activities that are often highly routinebound within certain time constraints, and non-negotiable [10]. The value of eco-forecasting for shifting this electricity consumption depends on the family's flexibility within their daily routines, and the challenges and opportunities of influencing these routines needs to be investigated. However, in line with [1] our results also show that the biggest potential gain from eco-forecasts is from time shifting of appliances that can be de-coupled from daily routines. In our study these were particularly identified as dishwashers, washing machines, and computer chargers, but in the future this could also include electric heat pumps and charging of electric cars. For these types of appliances we found that the challenge is not so much about domestic routines, but more about bridging between ecoforecast and appliance control, for example, telling the washing machine to run, or the electric car to charge, when electricity is green and in capacity. This challenge is both a matter of partial automation, and of interaction design.

\section{ACKNOWLEDGEMENTS}

This work is a part of TotalFlex funded by Energinet.dk

\section{REFERENCES}

1. Costanza, E., Fisher, J.E., Colleu, J.A., Rodden, T., Ramchurn, S.D., Jennings N.R. Doing the Laundry with Agents: a Field Trial of a Future Smart Energy System in the Home. Proc. CHI'14, ACM (2014), 823-832

2. Froehlich, J., Findlater, L., and Landay, J. The design of eco-feedback technology. Proc. CHI'10, ACM (2010), 1999-2008

3. Froehlich, J., Findlater, L., Ostergren, M., Ramanathan, S., Peterson, J., Wragg, I., Larson, E., Fu, F., Bai, M., Patel, S. and Landay, J. A. The design and evaluation of prototype eco-feedback displays for fixture-level water usage data. Proc. CHI'12, ACM (2012), 2367-2376

4. Kjeldskov, J., Skov, M. B., Paay, J. and Pathmanathan, R. Using mobile phones to support sustainability: A field study of residential electricity consumption. Proc. CHI'12, ACM (2012), 2347-2356

5. Mankoff, J. C., Blevis, E., Borning, A., Friedman, B., Fussell, S. R., Hasbrouck, J., Woodruff, A., and Sengers, P. Environmental sustainability and interaction. Ext. Abstracts of CHI'07, ACM (2007), 2121-2124

6. Pathmanathan, R., Pearce, J., Kjeldskov, J. and Smith, W. Using Mobile Phones for Promoting Water Conservation. Proc. OzCHI'11, ACM (2011), 243-252

7. Pierce, J. and Paulos, E. Beyond Energy Monitors: Interaction, Energy, and Emerging Energy Systems. Proc. CHI'12. ACM (2012), 665-674

8. Pierce, J., Schiano, D., and Paulos, E. Home, Habits, and Energy: Domestic Interactions and Energy Consumption. Proc. CHI'10. ACM (2011), 1985-1994

9. Schrammel, J., Gerdenitsch, C., Weiss, A., Kluckner, P., and Tscheligi, M. FORE-Watch - The Clock that Tells You When to Use. Proc AmI'11, LNCS (2011), 157-166

10.Strengers, Y. Designing eco-feedback systems for everyday life. Proc. CHI'11, ACM (2011), 2135-2144

11. Yang, R., Newman, M.W., and Forlizzi, J. Making Sustainability Sustainable: Challenges in the Design of Eco-Interaction Technologies. Proc. CHI'14, ACM (2014), 823-832 